\title{
Iterative Solution Method in Semiconductor Equations
}

\author{
Norainon Mohamed, Muhamad Zahim Sujod \\ and Mohamad Shawal Jadin \\ Universiti Malaysia Pahang, Lebuhraya Tun Razak, 26300 Kuantan, Pahang \\ Malaysia
}

\section{Introduction}

The FEM (sometimes referred to as finite element analysis (FEA)) is a numerical technique for finding approximate solutions of partial differential equation as well as of integral equations. The solution approach is based either an approximating system of ordinary differential equations, which are then solved using standard techniques such as Newton Method. It is the objective of this paper to describe the application of the method to device simulation. The device which described in this paper is Silicon Carbide Gate Turn-Off Thyristor (SiC-GTO Thyristor). The doping profile with the material properties of the device can be modelled. This paper specifically focuses on the numerical simulation of the device compare with the common Silicon GTO Thyristor.

The main advantages of the FEM are that conservation laws (e.g., current conservation) are exactly satisfied even by coarse approximations, it is easy to treat irregular geometries, the computational mesh can be graded to be fine in regions to rapid change, local mesh refinement is easier to implement than finite difference method (FDM).

In the following sections, the finite element equations which are arise from the semiconductor equations are derived and it is shown the equations are the base of semiconductor device simulations. The implementation of finite element equations will be discussed in the next section. For detailed discussion of the numerical simulation, it is in the results and discussion section.

\section{Numerical Method}

\subsection{Semiconductor Equations}

The semiconductor equations are a set of five equations that govern the behavior of semiconductor materials and devices. The set of equations composed of:

Poisson's equation

$$
\nabla^{2} \psi=\frac{q}{\varepsilon}\left(n-p-N_{d}\right)
$$

Current Continuity equations 


$$
\begin{gathered}
q \frac{\partial p}{\partial t}=-\nabla \cdot \mathbf{J}_{\mathbf{p}}-q R \\
q \frac{\partial n}{\partial t}=\nabla \cdot \mathbf{J}_{\mathbf{n}}-q R
\end{gathered}
$$

Drift-Diffusion equations

$$
\begin{aligned}
& \mathbf{J}_{\mathbf{p}}=q\left(p \widetilde{v}_{p}-D_{p} \nabla p\right) \\
& \mathbf{J}_{\mathbf{n}}=q\left(p \widetilde{v}_{n}-D_{n} \nabla n\right)
\end{aligned}
$$

In these equations, the three unknown quantities are the space-charge potential $(\psi)$, the electron (n) and hole (p) densities, $N_{d}$ is the doping densities, the constant $\mathrm{q}$ is the magnitude of electronic charge and $\varepsilon$ is the dielectric permittivity. $\mathbf{J}_{\mathbf{p}}$ and $\mathbf{J}_{n}$ are the hole and electron current densities. $\mathrm{R}$ is the recombination rate. $\widetilde{v}_{p}$ and $\widetilde{v}_{n}$ are the hole and electron drift velocities. $D_{p}$ and $D_{n}$ are the hole and electron diffusion coefficients.

The diffusion coefficients and drift velocities are electric field dependent and so the equations are nonlinear. The recombination term which is also nonlinear may be approximated by its thermal equilibrium value (Shockley Read Hall Theory).

\subsection{Finite Element Equations}

To solve (1) to (5), boundary conditions for the space-charge potential and electron and hole charge carrier densities are required. The finite element equations are derived from (1) to (3) by multiplying them by $\Phi_{\mathrm{i}}(\mathrm{x}, \mathrm{y})$ and integrating over the region $\Omega$ occupied by the device[4].

$$
\begin{aligned}
& \int_{\Omega} \Phi_{i}(x, y) \nabla^{2} \psi d s= \\
& -\frac{q}{\varepsilon} \int_{\Omega}(x, y)\left(p-n-N_{d}\right) d s
\end{aligned}
$$




$$
\begin{gathered}
\frac{1}{q} \int_{\Omega} \Phi_{i}(x, y) \nabla \mathbf{J}_{p} d s= \\
\int_{\Omega} \Phi_{i}(x, y)\left(\frac{\partial p}{\partial t}+R\right) d s \\
-\frac{1}{q} \int_{\Omega} \Phi_{i}(x, y) \nabla \mathbf{J}_{n} d s= \\
\int_{\Omega} \Phi_{i}(x, y)\left(\frac{\partial n}{\partial t}+R\right) d s
\end{gathered}
$$

\subsection{Final Form of Equations}

In computer solution by the finite element method there are four stages:

1. Read in (or generate internally) material properties- $\mathrm{Si}$ and $\mathrm{SiC}$ ) and element connectivity (mesh).

2. Assemble the equations (6), (7) and (8) which the finite element equations and inserting boundary conditions.

3. Solve the resulting linear equations

4. Repeat 2 and 3 iteratively for nonlinear and/or time dependent problems.

\section{Simulation Flow}

The simulation systems have been implemented by using MATLAB/Simulink surrounding. The simulation process is used Poisson's equation together with current continuity and drift-diffusion equations to simulate the performances of SiC GTO thyristor. Figure 1 shows the schematic structure of the simulator. Each phase describes complex process which involves the physical models along with the basic semiconductor equations as the basis to simulate the GTO performances.

The simulation process is controlled by the Material Input Database in each phase. The red line indicates the connection with the material database. Material Input Database is initialized at the initialization process. The basic structure of SiC GTO thyristor is initialized. The device structure and circuit definitions and additional information like material properties are loaded from the Material Input Database.

In the next step, the device or the circuit and its embedded devices are loaded and analyzed. For each segment of each device the material is determined. In the calculations steps, the basic semiconductor equations along with the physical models are solved by using numerical method, finite element method. The method is a powerful method for solving partial differential equations which involves lots of integral and differential. The method is used because of its approximation to the solution of the equation. In the postprocessing, the output quantities are calculated from the computed solution. 


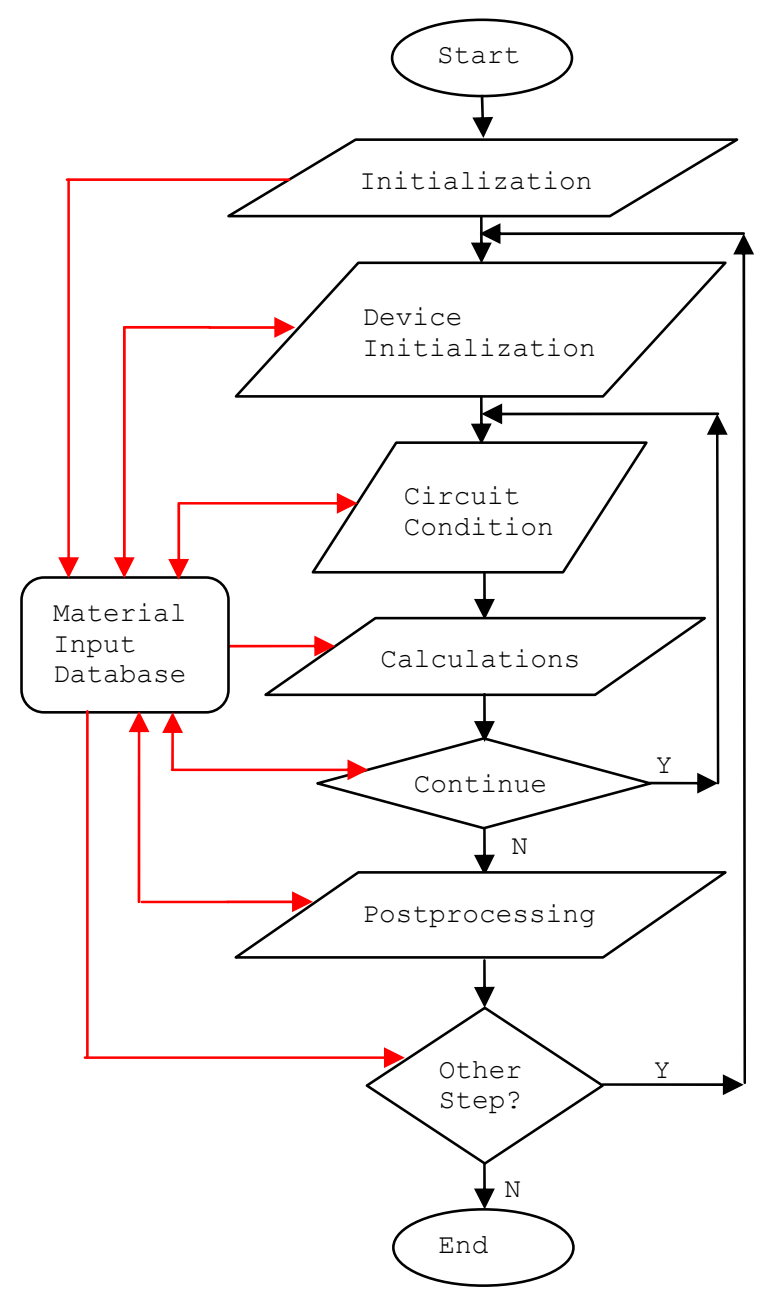

Fig. 1. Simulation flow of the device.

\section{Calculation Method}

The full set of semiconductor equations are solved numerically. As for discretization of space, the Scharfetter-Gummel scheme and the standard three-point formula are used formula are used for the Poisson's Equation and the continuity equation, respectively. These difference equations are solved based on Newton method. 


\section{Results and Discussions}

\subsection{Turn-on Characteristics}

Figure 2 shows the single-shot GTO thyristor turn-on voltage and current waveforms. These waveforms show the GTO thyristor's switching characteristics such as turn-on delay and turn-on rise time. The turn-on delay, is defined when the gate current, Ig, rises to $10 \%$ of its peak and when the GTO thyristor anode voltage, Va, falls to $90 \%$ of its initial value. From the figure 2, GTOs are turned on when the anode current is increased, the anode voltage is decreased. Then they are turned off by the negative gate pulse.

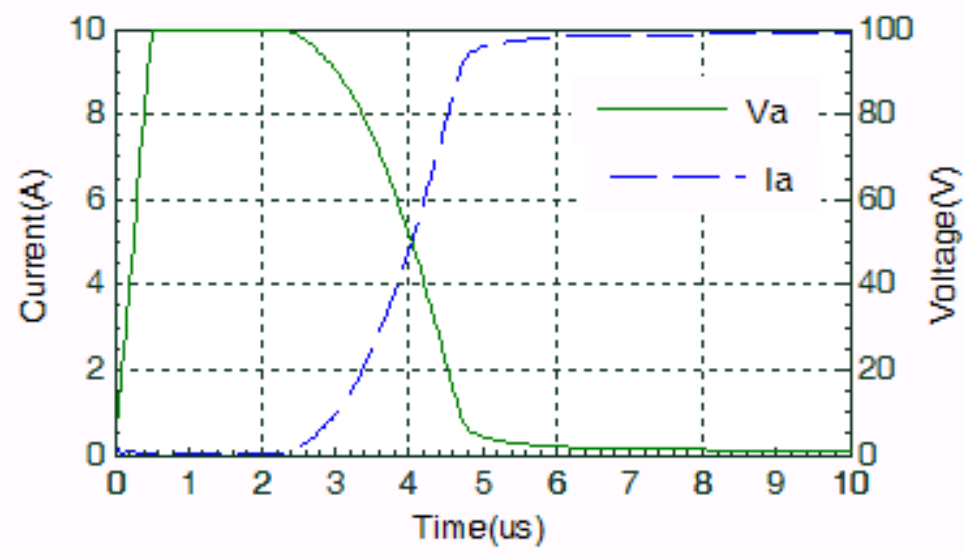

(a)

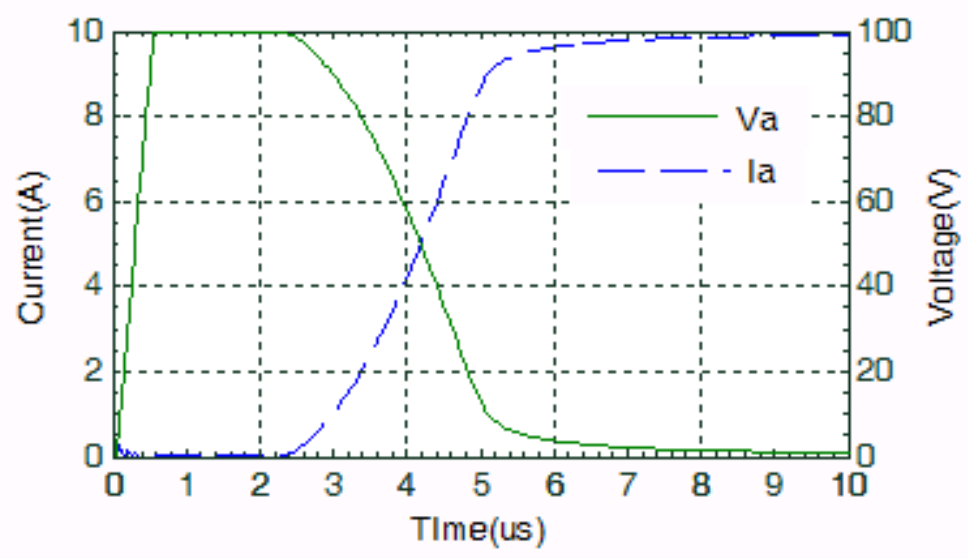

(b)

Fig. 2. Single-shot GTO thyristor turn-on characteristics (a) Si GTO thyristor anode voltage and current (b) SiC GTO thyristor anode voltage and current. 


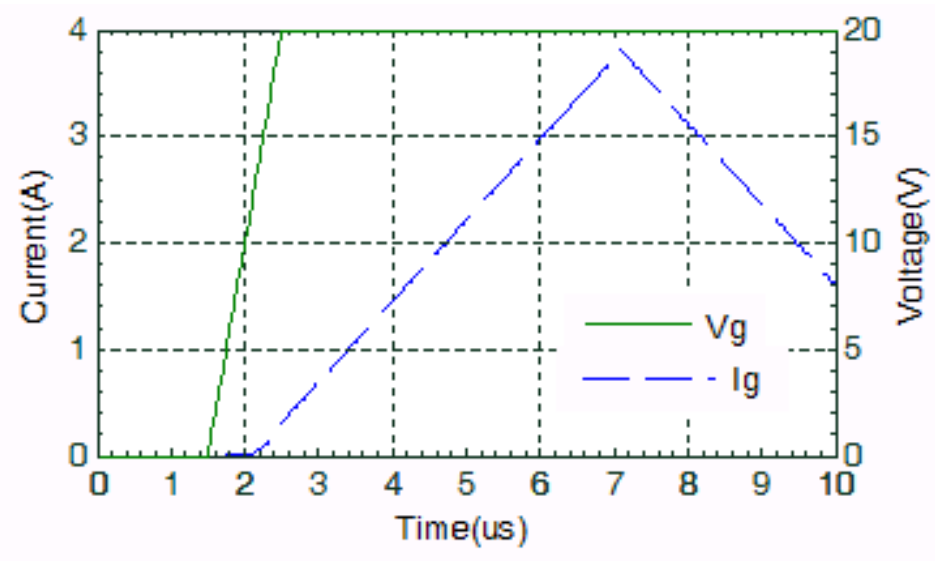

(c)

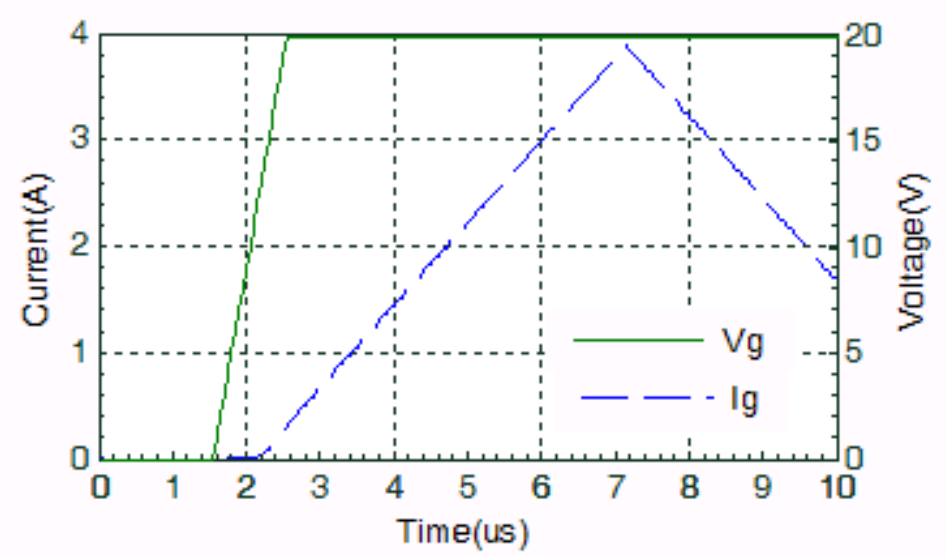

(d)

Fig. 2. Single-shot GTO thyristor turn-on characteristics (c) Si GTO thyristor gate voltage and current (d) SiC GTO thyristor gate voltage and current.

\subsection{Turn-off Characteristics}

The GTO thyristor turn-off as a function of time is given in figure 5. The GTO thyristor turn-off time was investigated as a function time. We can see the large difference at turn-off time of $\mathrm{SiC}$ GTO thyristor waveforms. We know that turn off time of SiC GTO thyristor is better than that Si GTO thyristor. The turn-on and turn-off time are shown in Table II (all units in us). Result show that switching time of SiC-GTO is decreased extremely and the performance of $\mathrm{SiC}$ in $\mathrm{GTO}$ is in the storage time, fall time and tail time. 


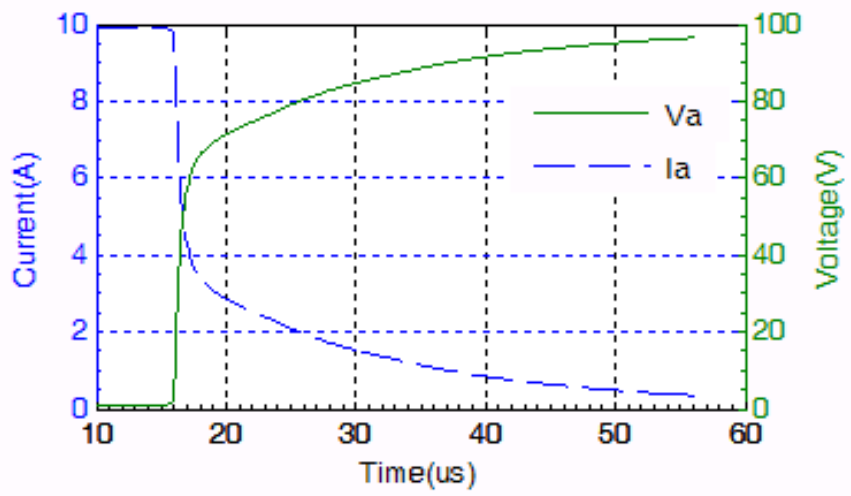

(a)

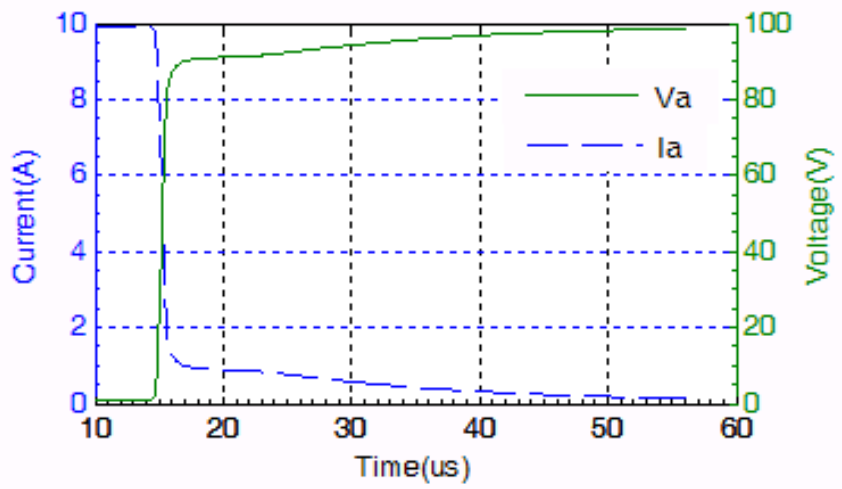

(b)

Fig. 3 Single-shot GTO thyristor turn-off characteristics (a) Si GTO thyristor anode voltage and current (b) SiC GTO thyristor anode voltage and current

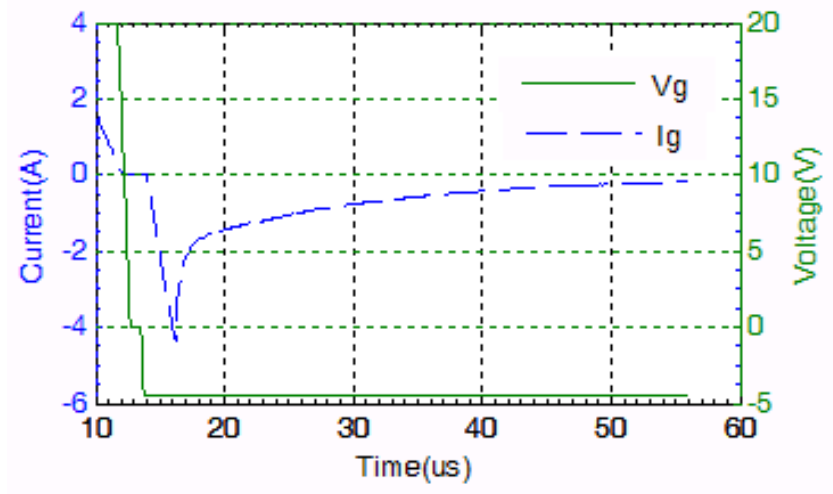

(c) 


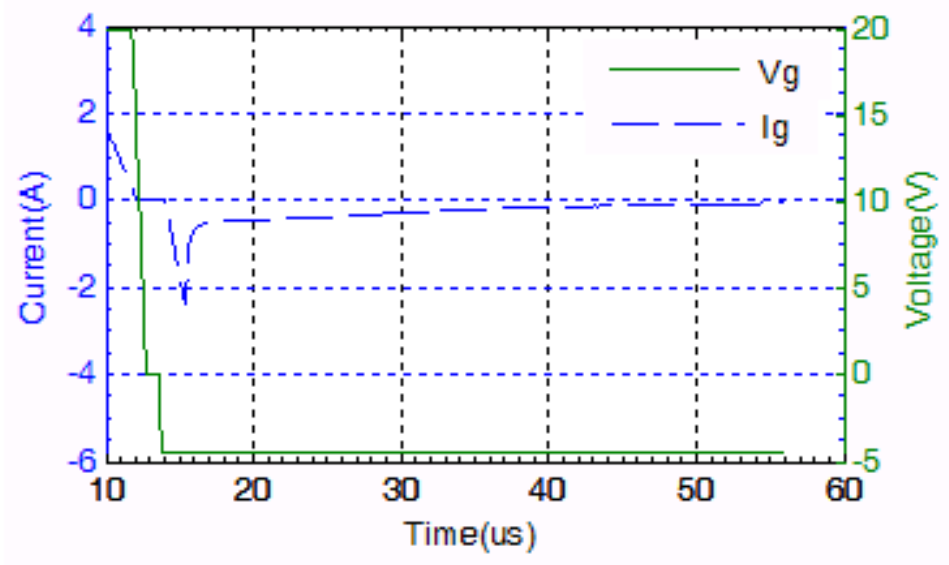

(d)

Fig. 3 Single-shot GTO thyristor turn-off characteristics (c) Si GTO thyristor gate voltage and current (d) SiC GTO thyristor gate voltage and current.

\begin{tabular}{|r|c|c|}
\hline & Si GTO & $\begin{array}{c}\text { SiC } \\
\text { GTO }\end{array}$ \\
\hline Turn-on time (us) & 3.00 & 3.00 \\
\hline Delay Time & 1.45 & 1.45 \\
\hline Rise Time & 1.55 & 1.55 \\
\hline Turn off time (us) & 82.5 & 62.2 \\
\hline Storage time & 15.9 & 14.7 \\
\hline Fall time & 17.3 & 15.4 \\
\hline Tail time & 49.4 & 32.1 \\
\hline $\begin{array}{l}\text { Switching Time } \\
\text { (us) }\end{array}$ & $\mathbf{8 5 . 5}$ & $\mathbf{3 2 . 1}$ \\
\hline
\end{tabular}

Table 1. Switching time of Si and SiC GTO Thyristors.

\section{Conclusion}

We compared the switching waveforms of usual Si GTO thyristor and new SiC GTO thyristor under inductive load. Turn off time is smaller in the case of SiC GTO thyristor than in that Si GTO thyristor.

\section{References}

A. R. Powell \& L. B. Rowland, "SiC Materials progress, Status \& Potential Roadblocks," Proc. IEEE, vol. 90, no. 6, pp. 942-955, 2002.

J. A. Cooper, JR., and A. Agrawal, "SiC Power Switching Devices The Second Electronic Revolution?" Proc. of the IEEE, vol. 90, pp. 956-968, 2002. 
A. K. Agarwal, P. A. Ivanov, M. E. Levinshtein, J. W. Palmour, S. L. Rumyantsev, S. H. Ryu and M. S.Shur, "Turn-off Performance of a $2.6 \mathrm{kV} 4 \mathrm{H}-\mathrm{SiC}$ Asymmetrical GTO Thyristor," Material ScienceForum, vol. 353-356, pp 743-746,2001.

R. R. Siergiej, J. B. Casady, A. K. Agarwal, L. B.Rowland. S. Seshadri, S. Mani, P. A. Sanger and C.D. Brandt, "1OOOV 4H-Sic Gate Turn Off (GTO)Thyristor," Compound Semiconductors, IEEEInternational Symposium, pp. 363-3156. 1997.

A. K. Agarwal. P. A. Ivanov, M. E. Levinshteitl, J.W. Palmour, S. L. Rumyantsev, S. H. Ryu, and M. S .Shur, "Turn-off performance of a $2.6 \mathrm{kV} 4 \mathrm{H}-\mathrm{SiC}$ Asymmetrical GTO Thyristor," Material Science Forum, pp. 353-356.

D.L. Scharfetter and H.K. Gummel, Large-Signal Analysis of A Silicon, IEEE Trans. Electron Devices, vol. ED-16,pp 64-77, Jan 1969.

J. B. Fedison, "High Voltage Silicon Carbide Junction Rectifiers and GTO Thyristors", PhD Thesis, Rennsealer Polytecnic Institute, New York, May 2001.

H. Sakata, M. Zahim, "Device Simulation of SiC-GTO", IEEE Power Conversion Conference", vol. 1, April 2002, pp. 220-225. 


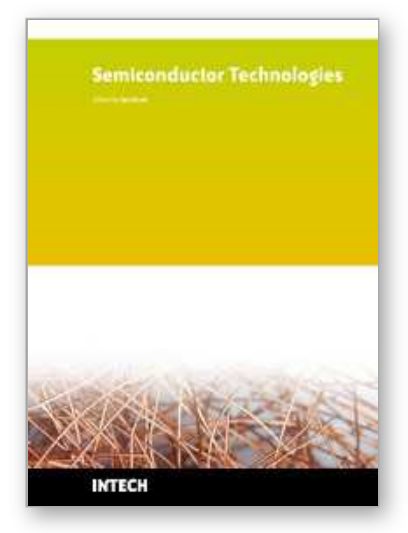

\section{Semiconductor Technologies \\ Edited by Jan Grym}

ISBN 978-953-307-080-3

Hard cover, 462 pages

Publisher InTech

Published online 01, April, 2010

Published in print edition April, 2010

Semiconductor technologies continue to evolve and amaze us. New materials, new structures, new manufacturing tools, and new advancements in modelling and simulation form a breeding ground for novel high performance electronic and photonic devices. This book covers all aspects of semiconductor technology concerning materials, technological processes, and devices, including their modelling, design, integration, and manufacturing.

\section{How to reference}

In order to correctly reference this scholarly work, feel free to copy and paste the following:

Norainon Mohamed, Muhamad Zahim Sujod and Mohamad Shawal Jadin (2010). Iterative Solution Method in Semiconductor Equations, Semiconductor Technologies, Jan Grym (Ed.), ISBN: 978-953-307-080-3, InTech, Available from: http://www.intechopen.com/books/semiconductor-technologies/iterative-solution-method-insemiconductor-equations

\section{INTECH}

open science | open minds

\author{
InTech Europe \\ University Campus STeP Ri \\ Slavka Krautzeka 83/A \\ 51000 Rijeka, Croatia \\ Phone: +385 (51) 770447 \\ Fax: +385 (51) 686166 \\ www.intechopen.com
}

\author{
InTech China \\ Unit 405, Office Block, Hotel Equatorial Shanghai \\ No.65, Yan An Road (West), Shanghai, 200040, China \\ 中国上海市延安西路65号上海国际贵都大饭店办公楼 405 单元 \\ Phone: +86-21-62489820 \\ Fax: $+86-21-62489821$
}


(C) 2010 The Author(s). Licensee IntechOpen. This chapter is distributed under the terms of the Creative Commons Attribution-NonCommercialShareAlike-3.0 License, which permits use, distribution and reproduction for non-commercial purposes, provided the original is properly cited and derivative works building on this content are distributed under the same license. 